\title{
As identidades negras da diáspora e a descolonização da representação
}

\section{Lucianna Sousa Furtado Brito e Laura Guimarães Corrêa}

\section{Resumo}

Este artigo teórico apresenta uma reflexão sobre as identidades culturais da diáspora negra, investigando sua constituição por meio da multilocalidade, dos processos históricos coloniais de objetificação racial e das práticas de resistência negra nas dimensões individual e coletiva, centralizando a dimensão compartilhada por sua diversidade e pluralidade. Abordando o uso das imagens e das formas de representação como mecanismo para a naturalização das hierarquias raciais, este estudo discute a ruptura com o projeto colonial, por meio do desenvolvimento da consciência crítica junto a novos olhares e perspectivas, e apresenta os pontos de convergência nos discursos identitários da diáspora negra.

\section{Palavras-Chave}

Diáspora negra. Racismo. Interseccional.

\section{Lucianna Sousa Furtado Brito}

Mestranda do Programa de Pós-Graduação em Comunicação Social da Universidade Federal de Minas Gerais, Belo Horizonte, Minas Gerais, Brasil. E-mail: lucianna.furtado@gmail.com https://orcid.org/0000-0002-4818-9370

\section{Laura Guimarães Corrêa}

Doutorado em Comunicação Social pela Universidade Federal de Minas Gerais, Brasil. Professora adjunta da Universidade Federal de Minas Gerais, Belo Horizonte, Minas Gerais, Brasil. E-mail: guimaraes.laura@gmail.com https://orcid.org/0000-0002-7218-1782

\section{Introdução}

0 processo histórico da colonização junto ao tráfico intercontinental de africanos escravizados e movimentos migratórios globais complexificaram as interações raciais e a forma como a construção social da raça articula significados de diferença e práticas de exclusão. 0 objetivo deste artigo teórico é sistematizar uma revisão bibliográfica acompanhada de uma reflexão crítica sobre as identidades da diáspora negra, investigando sua constituição nas relações com a matriz africana, com as comunidades locais e entre si, em busca dos aspectos centrais que orientam seus discursos.

Para isso, o trabalho abordará o conceito de diáspora e as especificidades da vertente africana, historicizando a construção social da negritude por meio dos processos coloniais de atribuição de identidades fixas e inferiorizadas, junto à representação nos meios de comunicação como mecanismos da dominação racial.

0 artigo contemplará as práticas de contestação, descolonização, desenvolvimento 
do olhar crítico e organização coletiva pelos direitos civis, realizadas pelas pessoas negras, como formas de resistência, apresentando pontos de convergência entre os discursos identitários da diáspora negra. Sem pretender homogeneizar essa vasta diversidade de experiências, tampouco subestimar a materialidade das particularidades locais na formação das identidades diaspóricas, mobiliza-se 0 conceito de diáspora com 0 intuito de focar os aspectos em comum que constroem e consolidam a conexão entre os filhos da diáspora negra. Desse modo, 0 artigo enfatizará a dimensão compartilhada dessas práticas de resistência, referentes às formas de representação e de construção das imagens, nos meios de comunicação, que reverberam marcas da colonização na constituição discursiva e cultural como forma de legitimação do racismo em sua dimensão de violência e desigualdade estrutural.

\section{A diáspora negra}

0 conceito de diáspora, originado para designar a dispersão geográfica das populações judaicas em migrações forçadas ou voluntárias, é usado na contemporaneidade para se referir, mais amplamente, à dispersão de uma miríade de grupos étnico-raciais entre diversas localizações. Como destaca Avtar Brah (1996), diásporas não são homogêneas, mas formações mistas constituídas por uma diversidade de experiências históricas e dotadas de particularidades específicas, como um entrelaçamento de múltiplas jornadas e narrativas.

Pensar em diáspora, para Brah (1996), implica as condições econômicas, políticas e culturais que conectam as trajetórias de um grupo étnico-racial que compartilha a mesma origem, em uma confluência de narrativas articulada em processos individuais e coletivos de memória e re-memória. Nessa perspectiva, a mobilização do conceito de diáspora enfatiza precisamente essa matriz de inter-relações que constituem um domínio comum entre os componentes do grupo dispersado, delineando um campo de identificações. Na visão de Brah (1996), a identidade da comunidade diaspórica não é fixa, predeterminada, mas constituída na materialidade da vida cotidiana e das narrativas socialmente construídas.

As principais características das diásporas, segundo Safran (1991, apud CLIFFORD, 1994, p. 305) são: um histórico de dispersão; mitos e memórias da terra natal; alienação no país anfitrião; desejo de retorno; apoio contínuo à pátria de origem; e uma identidade coletiva fortemente marcada por essa relação. Clifford (1994) ressalta que essa definição, ao partir da diáspora judaica tradicional como modelo normativo, mostra-se excessivamente restrita e não contemplaria, por exemplo, a diáspora africana, que se configura de maneira descentralizada e não necessariamente orientada pelo desejo de retorno. 
Para 0 autor (1994), esses vínculos paralelos e descentralizados, reunificados pelo compartilhamento de processos contínuos de deslocamento, opressão, adaptação ou resistência, são tão significativos quanto a teleologia do retorno. Brah (1996) reafirma que nem todas as diásporas focam o retorno físico, e que a pátria de origem pode se manifestar na multilocalidade que marca a construção de suas identidades, subjetividade e imaginário coletivo. Como aponta Kim Butler (2001), a construção sociocultural da terra natal é essencial para a identidade diaspórica - não obrigatoriamente pelo retorno, mas emergindo nos saberes, costumes, no imaginário ancestral, na sensação de conexão e pertencimento.

Clifford aponta que algumas dimensões da própria diáspora judaica, tomada como modelo normativo, já não preenchem todos os requisitos apontados por Safran (1991, apud CLIFFORD, 1994), propondo não se fixar em um modelo obsoleto, mas investigar e mapear a diversidade de formas diaspóricas. Como a diáspora africana é formada majoritariamente por descendentes de africanos escravizados, levados à força para outros continentes e privados de registros, é comum a impossibilidade de traçar essa origem específica no continente africano, 0 que inviabiliza sua orientação para o retorno. Processos de descolonização e resistência, como a recusa ao eurocentrismo na adoção de referências culturais, intelectuais e estéticas afrocêntricas, são alternativas consistentes à teleologia do retorno como vínculo com a terra de origem.

Conforme o mapeamento conceitual de Butler (2001, p. 192), parte significativa dos pesquisadores da área concorda quanto a três características básicas. A primeira é a dispersão populacional em uma disseminação para dois ou mais locais, em oposição à transferência para um destino único, visto que essa dispersão é o que dá origem aos vínculos em locais distintos. 0 segundo ponto é um relacionamento com uma terra natal, seja esta real, seja socialmente construída, que servirá como alicerce para a identidade diaspórica. A terceira característica é a autoconsciência de sua identidade coletiva, conscientemente construída e mantida, que não apenas vincula os sujeitos à terra de origem, como os conecta entre si. A autora acrescenta um quarto aspecto, ligado à dimensão temporal e histórica da diáspora, que é um mínimo de duas gerações - do contrário, se trataria de um exílio temporário. Em sua visão, diásporas são necessariamente multigeracionais e combinam a experiência migratória individual com a história coletiva de dispersão e recriação de comunidades em outros locais.

\section{Cultura, identidade e consciência da diáspora}

Cultura, segundo Brah (1996), é a construção simbólica do conjunto de experiências de um 
grupo social; a corporificação de sua história, entremeadas pelas condições materiais, marcadas pelas configurações sociais e econômicas desse grupo em seus múltiplos estágios históricos. Para a autora, culturas não são fixas ou estáticas, mas evoluem ao longo do tempo: embora sejam socializados para aprender e reproduzir tradições, os sujeitos atuam sobre elas por meio da aceitação ou recusa; de reiteração ou repúdio; de modo que as práticas sociais nas interações cotidianas podem filtrar e transformar essas tradições. A cultura e a construção de significados sociais estão fortemente ligadas à formação das identidades junto às experiências individuais e coletivas. A identidade, para Brah (1996), é simultaneamente subjetiva e social, constituída na cultura e por meio da cultura, de modo que esses dois conceitos estão intrinsecamente vinculados um ao outro.

Sobre o pertencimento da diáspora, Clifford (1994) aponta que mesmo as ideologias nacionais de assimilação, cujas narrativas de unificação acolhem imigrantes sob a noção de integração, tendem a não contemplar populações diaspóricas, devido à sua história coletiva de deslocamento, perda, violência e preconceito contínuo. Segundo 0 autor, esse processo de imigração, acolhimento e integração nunca funcionou plenamente para africanos e seus descendentes no Novo Mundo, escravizados ou imigrados livremente, devido ao racismo e à exclusão estruturais que regem essas interações e esses lugares sociais.
Para Clifford (1994), as diásporas desempenham relações de tensionamento, adaptação e resistência com as narrativas nacionalistas hegemônicas do país anfitrião, tendo sua cultura ligada aos regimes de dominação política e desigualdade econômica que permeiam seus deslocamentos. Desse modo, são marcadas por relações paradoxais e ambíguas entre assimilação e diferenciação, integração e rejeição; marcadas pela opressão estrutural como uma ruptura na assimilação; complexificadas pela negociação entre pertencimento/aceitação e exclusão/discriminação; desenvolvendo relações de identificação e desidentificação, da multilocalidade que permeia as identidades da diáspora.

No período pós-colonial, a diáspora negra no Reino Unido articulou novas identidades, negociadas entre permanecer e ser diferente, entre ser britânico e ser algo mais: uma identidade relacionada à África e às Américas em histórias compartilhadas de escravidão, subalternização, racismo, hibridização e resistência (CLIFFORD, 1994). Para 0 autor, essa formação evidencia o termo "diáspora" como um significante não apenas de transnacionalidade e dispersão, mas de cooperação em lutas políticas nas comunidades locais.

Esse movimento está relacionado ao que Clifford (1994) chama de consciência da diáspora ("diaspora consciousness"), originada de duas vertentes. Na dimensão positiva, ela emerge da identificação com a construção social da origem, própria ou de antepassados, criando uma identidade local "diferente". Negativamente, 
está ligada à exclusão racial e à desigualdade socioeconômica que levam à organização coletiva para sobrevivência. 0 autor evidencia que podem emergir novas alianças dessa marginalização: na década de 1970, quando o termo "negro" era usado no Reino Unido para discriminar imigrantes de pele escura sul-asiáticos, afrocaribenhos e africanos, esses grupos uniram-se em movimentos trabalhistas antirracistas.

Outro exemplo de alianças políticas entre grupos culturais distintos é a própria diáspora africana. Como avaliado por Butler (2001), a heterogeneidade cultural dos descendentes de africanos escravizados, trazidos de diversas nações da África para as Américas, poderia ter sido desfavorável à solidariedade e à união. No entanto, a discriminação, exclusão e violência baseadas no pertencimento étnico-racial negro levaram à formação de laços de cooperação nas comunidades diaspóricas africanas, apesar da sua multiplicidade étnico-cultural. A autora enfatiza esse contato entre comunidades da diáspora, independente do contato com a terra ancestral, como vital na construção da consciência diaspórica e na formação de instituições e redes de apoio.

Na transformação das comunidades locais, Angela Davis (2016) centraliza 0 acesso à educação nas lutas da diáspora negra estadunidense. Esse é um movimento que tensiona e contraria a ideia hegemônica do país de que, por ter sido propriedade de outros e supostamente inferior, a população negra era incapaz de progressos intelectuais. A autora (2017) traça um paralelo entre as práticas educacionais da dominação branca sobre as diásporas negras na África do Sul, em Granada e nos Estados Unidos, dedicadas ao ensino da hierarquização racial, à colonização das mentes negras e seu confinamento à subalternidade.

Em toda diáspora africana, condições legais, econômicas e sociais impedem ou limitam significativamente 0 acesso da população negra à educação formal, à ascensão em carreiras acadêmicas e em profissões intelectualizadas, de prestígio e poder financeiro. 0 desenvolvimento intelectual não ocorre, porém, apenas na educação tradicional, mas em diversas formas de transmissão e criação de saberes, entremeados nas práticas culturais e na sociabilidade da diáspora negra por meio da oralidade, da música, da arte, em formatos dinâmicos e dialógicos de construção do conhecimento. No entanto, a educação formal recebe um reconhecimento e uma legitimação social não atribuídos às tradições orais de grupos subalternizados. A hierarquização e 0 apagamento de saberes, ciências, culturas e formas de conhecimento representam uma dimensão significativa da estrutura racista.

Abordando a arte como uma forma de consciência social que desperta práticas criativas de transformação da opressão, Davis (2017) atribui às manifestações artísticas um potencial 
sensibilizador e catalisador, de promover a participação em movimentos sociais:

A arte progressista pode ajudar as pessoas a aprender não apenas sobre as forças objetivas em ação na sociedade em que vivem, mas também sobre 0 caráter intensamente social de suas vidas interiores. Em última análise, ela pode incitar as pessoas no sentido da emancipação social (DAVIS, 2017, p. 166).

Na perspectiva da autora, essas formas de arte aceleram o progresso social ao contestar a cultura dominante, o que é evidenciado na relação entre a música negra estadunidense e as lutas pelos direitos civis. Davis afirma que a função social da música na tradição africana passou despercebida pela escravocracia, e os cantos escaparam às proibições: "Em consequência disso, o povo negro foi capaz de criar com sua música uma comunidade estética de resistência que, por sua vez, encorajou e nutriu uma comunidade política de luta ativa pela liberdade" (2017, p. 167). Para a autora, a arte progressista e revolucionária só é concebível associada a movimentos políticos radicais pela transformação social.

A consciência diaspórica não surge, portanto, automaticamente, mas depende desse contato entre os grupos, da construção de um imaginário de unificação e identificação em torno da história compartilhada e da opressão contemporânea. Para Butler (2001), a diáspora africana existiu por aproximadamente quatro séculos antes de ser posta em prática. Antes de construírem uma identidade coletiva em torno da negritude, as comunidades afro-atlânticas poderiam ter seguido outras trajetórias de assimilação, como os afro-hispânicos que optaram por identidades hispânicas em vez de identidades negras (BUTLER, 2001, p. 207). Nessa perspectiva, a identidade é fundamental na constituição diaspórica, transformando-as a partir da realidade física da dispersão para a construção da realidade psicossocial da diáspora.

Para Stuart Hall (1990), as identidades da diáspora são constantemente produzidas e reproduzidas, em processos de transformação e diferenciação por meio do reconhecimento da diversidade e heterogeneidade, em uma identidade que não se constitui apesar da diferença, mas por meio dela, em processos de hibridização. Hall define a identidade cultural negra nas Américas como a articulação entre a presença africana da origem, a europeia da colonização e a americana do novo continente onde essa identidade foi hibridizada - não de forma igualitária, mas por meio das relações de poder, dominação e resistência entre essas três dimensões. Na perspectiva do autor, enquanto a presença africana foi silenciada, sufocada, a presença europeia se impôs como voz predominante; como a voz que nomeia, define, atribui significados e hierarquias no sistema colonial; como símbolo da exclusão, imposição e expropriação.

A identidade cultural, portanto, é uma questão de "se tornar" tanto quanto de "ser" (HALL, 
1990, p. 225). Para Hall, essa identidade não é uma essência fixa, intacta, à parte da história e da cultura, mas se relaciona aos processos históricos, aos seus efeitos materiais e simbólicos, em constante transformação. Como observa 0 autor, mesmo em referências ao passado histórico, essa identidade não aciona um passado essencialista nem se prende ao mero resgate de um passado estático - ela historiciza as narrativas do passado e suas relações de poder, elaborando como estas posicionam socialmente os sujeitos e, por meio da construção dessa identidade, como os sujeitos se posicionam diante delas. A retomada do passado não trata simplesmente de desenterrar as continuidades suprimidas pela experiência colonial em uma redescoberta da identidade: trata-se da produção da identidade (HALL, 1990, p. 224).

Hall (1990) evidencia o caráter traumático da experiência colonial e suas reverberações contemporâneas, enfatizando que os regimes dominantes de representação nos meios de comunicação e sua imposição às pessoas negras correspondem a uma parte significativa dos processos de criação e manutenção das relações de poder. Na concepção do autor, as normas de representação não apenas construíram as pessoas negras como "diferentes", como "outro", mas atuaram para que as próprias pessoas negras vissem a si mesmos e a suas experiências como circunscritas a essa ideia de "outro" (HALL, 1990, p. 225). Nessa perspectiva, o processo da colonização não se referiu apenas aos corpos e ao trabalho, mas à colonização da cultura, do imaginário, das mentes das pessoas negras.

0 pensamento de Hall $(1990,2003)$ sobre o papel da política de representação na epidermização do racismo e inferioridade reverbera as contribuições teóricas de Frantz Fanon (2008)ํ․ Para 0 autor, a herança colonial, além da dimensão material e econômica, também colonizou as mentes, impondo o eurocentrismo e a branquitude como representativos da razão civilizadora, da beleza, do intelecto e da pureza.

Na Europa, o preto, seja concreta, seja simbolicamente, representa o lado ruim da personalidade. Enquanto não compreendermos esta proposição, estaremos condenados a falar em vão do 'problema negro'. 0 negro, o obscuro, a sombra, as trevas, a noite, os labirintos da terra, as profundezas abissais, enegrecer a reputação de alguém [...]. 0 arquétipo dos valores inferiores é representado pelo negro (FANON, 2008, p.160).

Fanon (2008) repudia o essencialismo atribuído às representações racistas, defendendo que as convenções socioculturais e 0 inconsciente coletivo não vêm de uma herança física, mas são consequência de uma imposição cultural irrefletida e incontestada. 0 autor enfatiza a atuação das formas de representação no sistema educacional, assim como em jornais, revistas, livros, cinema e 
outros meios de comunicação, na constituição do imaginário sobre o papel social das pessoas negras; na construção de sua imagem associada a selvageria, irracionalidade, vilania, desonestidade, inferioridade intelectual; na sua desumanização e seu confinamento à subalternidade.

Considerando o racismo em sua dimensão estrutural, econômica e também cultural, que atua nos processos sociais de significação, naturaliza essa hierarquização e legitima discursivamente essa violência material, Fanon (2008) propõe a completa reestruturação do mundo como forma de contestar esse cenário colonial e seus ecos contemporâneos. Abordando seus efeitos sobre a consciência das pessoas negras, 0 autor sugere a ação conjunta sobre 0 indivíduo e o grupo social, conscientizando a luta contra as hierarquias coloniais da supremacia branca, e orientando ações para a mudança das estruturas sociais. Portanto, para Fanon (2008), a superação da herança colonial deve contemplar a conquista de direitos civis e a descolonização das mentes das pessoas da diáspora negra.

As identidades da diáspora são construídas, portanto, mediante condições culturais e materiais, entremeando o imaginário da terra ancestral às conexões com outros grupos dessa diáspora e às relações locais de conflito $\mathrm{e}$ pertencimento. Segundo Butler, o elo com a terra de origem perpassa gerações e se manifesta no vínculo emocional artístico e na reinterpretação das culturas ancestrais na diáspora: "Grande parte da experiência da diáspora não está escrita: está inscrita nas artes criativas, na cultura material e nas tradições orais" (BUTLER, 2001, p. 212). Para a autora, a representação e reinterpretação podem ser mais significativas na construção da identidade diaspórica do que a própria realidade dessa terra ancestral.

Hall (2003) evidencia a rica cultura popular negra como um terreno de apropriação e rearticulação seletivas da cultura europeia junto às tradições africanas, produzindo novas formas de expressão, resistência, ocupação dos espaços sociais e fortalecimento de laços. 0 imaginário da terra ancestral, junto às experiências históricas e processos de codificação da memória, emerge nessas culturas populares:

Em sua expressividade, sua musicalidade, sua oralidade e na sua rica, profunda e variada atenção à fala; em suas inflexões vernaculares e locais; em sua rica produção de contranarrativas; e, sobretudo, em seu uso metafórico do vocabulário musical, a cultura popular negra tem permitido trazer à tona, até nas modalidades mistas e contraditórias da cultura popular mainstream, elementos de um discurso que é diferente - outras formas de vida, outras tradições de representação (HALL, 2003, p.342).

Desse modo, a diáspora negra não apenas resgata a referência africana, mas a reconstrói, por meio de memórias, mitos e símbolos estéticos acionados em suas culturas populares. Como enfatizado por Hall (1990), essa referência já não é um resgate concreto, mas a constituição do que essa África se tornou nas Américas, do imaginário 
desse continente ao ser renarrado na diáspora.

A referência à África e sua constante reconstrução são, portanto, questões centrais na identidade cultural da diáspora - não apenas como ponto de origem, mas como vínculo de reunificação entre seus povos fragmentados.

Para tratar da diáspora negra na América Latina, Lélia Gonzalez (1988) propõe observar as especificidades locais das relações coloniais, as teorias de miscigenação e assimilação, assim como suas reverberações contemporâneas nas dinâmicas culturais que organizam as interações entre as raças. Na visão da autora, o caráter rigidamente hierárquico das sociedades ibéricas, que submetia os mouros e judeus a um violento controle social e político, estendeu às colônias latino-americanas seu sistema de classificação e estratificação social por meio da raça. Desse modo, Gonzalez afirma que a igualdade de todos perante a lei constituiu-se sob um caráter apenas formalista, já que, na prática, essas sociedades mantêm pessoas negras e indígenas em um lugar de subordinação.

Na perspectiva de Gonzalez (1988), as sociedades latino-americanas constituíram o racismo por denegação, originado na racionalidade administrativa colonial que naturalizou a violenta dominação branca contra os povos ditos primitivos. Em sua visão, essas dinâmicas culturais sofisticaram a violência contra os colonizados, revestindo-a de uma máscara de legitimidade e superioridade natural. Nesse contexto, foi construído o mito da democracia racial, um cenário de suposta harmonia e mistura igualitária entre as raças no qual as hierarquias coloniais ainda influenciam a distribuição de poder, renda e legitimidade de fala. Gonzalez aponta que a ideologia de branqueamento que governa essas sociedades, veiculada, por exemplo, pelos meios de comunicação, perpetuam as classificações raciais e consolidam os valores eurocêntricos como norma.

Em contraponto às denominações "afroamericano" e "africanoamericano", que reproduzem a noção imperialista que centraliza os Estados Unidos como a América e ignora os demais países do continente, Gonzalez (1988) propõe uma nova forma de pensar a diáspora negra na América como um todo: os "amefricanos". A categoria de amefricanidade elaborada pela autora contempla os processos históricos de adaptação, resistência, reinterpretação e invenção criativa de maneira afrocentrada, ligada à diversidade de origens culturais africanas que a compõem - apontando-a como ponto de partida para uma identidade étnicoracial que não apenas afirma sua herança africana, mas reelabora e reconstrói essa matriz cultural em sua diáspora nas Américas.

\section{Representação e construção das identidades}

Conforme discutido na seção anterior, as políticas e práticas de representação exercem um papel significativo nas relações de poder, na constituição 
das identidades e naturalização do racismo. Para Hall (1990), esses processos implicam perspectivas, lugares sociais, posicionamentos de enunciação: os produtos culturais que constroem as figuras de representação operam não como um espelho secundário que meramente reflete o que já existe, mas como capazes de constituir novas maneiras de subjetividade, permitindo aos sujeitos a descoberta de novos lugares sociais de expressão, novas posições de enunciação.

Em vez de pensar em identidade como um fato consumado que as práticas culturais simplesmente representam, Hall propõe tomála como um processo produtivo que nunca se completa, que está sempre em construção por meio dos regimes de representação (1990, p. 222). Referindo-se ao cinema, 0 autor enfatiza que as produções negras modernas oferecem ao público negro a possibilidade de se verem e se reconhecerem em novas histórias de si mesmos, constituindo pontos de identificação com esses posicionamentos e atuando positivamente junto à construção das identidades culturais.

Em consonância com esse pensamento, bell hooks² (1992) afirma que a representação atua na socialização e no aprendizado de modo a naturalizar, internalizar e institucionalizar as normas de hierarquização racial que desumanizam pessoas negras. Para a autora, a construção de imagens da negritude para afirmar a superioridade branca, 0 imperialismo político e 0 desejo branco de dominar antecede a formação da diáspora negra, desde os primórdios do contato colonial com o continente africano. Segundo hooks, desde então a supremacia branca já reconhecia o controle sobre as imagens como central para a manutenção do sistema de dominação racial enfatizando, porém, que essa representação não é imperativa, dotada de poder absoluto, mas passível de desconstrução, contestação e resistência. Para hooks (1992), é importante não tomar os sujeitos como vítimas passivas da socialização, para não os eximir da responsabilidade de refletir criticamente sobre a reprodução de práticas culturais racistas e sobre a dimensão estrutural dessa opressão.

Abordando 0 olhar como um gesto político de resistência, dotado de potencial de questionamento, confronto e desafio à autoridade, hooks (1992) o relaciona à própria constituição do indivíduo como sujeito. Historicizando o imaginário desse gesto no contexto racializado das relações de poder, a autora aponta que pessoas negras escravizadas eram punidas por olhar fixamente, por olhar demais, por olhar sem permissão, sendo privadas do direito de dirigir o olhar conforme sua vontade. Para hooks, a tentativa de reprimir o olhar das pessoas negras fez com que ele emergisse como insubordinação, ato de rebelião, gesto crítico e oposicionista: 
ao afirmar 0 direito de olhar, declara-se também o desejo de mudar a realidade observada. Em sua concepção, o movimento do olhar é um espaço de resistência, no qual as pessoas negras podem se posicionar como sujeitos, contestar o olhar do Outro e nomear o que veem.

Desse modo, hooks (1992) analisa o contato das pessoas negras com a televisão e cinema mainstream estadunidenses como um gesto espectador consciente da atuação desses meios de comunicação na reprodução e manutenção da supremacia branca. Nos movimentos pelos direitos civis, os olhares negros desenvolveram-se cada vez mais como interrogadores, contestadores e críticos quanto aos modos de representar pessoas brancas e pessoas negras na cultura dominante. 0 papel do espectador, para hooks, pode ser de agência, principalmente na medida em que olha criticamente e recusa a identificação com a narrativa representada.

No processo de descolonização das mentes, hooks (1992) afirma que a representação negra e seus debates tendem a focar na problemática da aversão, do ódio; da denúncia; da impotência, da posição como vítima; da introjeção das normas raciais impostas pela cultura dominante e presentes na consciência coletiva das pessoas negras - propondo, então, que a produção passe a contemplar 0 amor à negritude ("loving blackness" no original), um potente ato de resistência. A ideia da autora é superar essa hierarquia racista e a busca pelo embranquecimento, promovendo a valorização da negritude e a construção de perspectivas positivas para a estética e as identidades negras.

Conforme aponta hooks (1992), as comunidades segregadas nos Estados Unidos representaram um espaço para experiências positivas da negritude, em oposição aos locais de integração racial nos quais a cultura dominante racista determina a maior parte das interações sociais. Apesar da violência, da violação de direitos e da profunda desigualdade social no contexto da segregação racial, a autora vê nessa comunidade negra um espaço seguro para promover a descolonização e estabelecer relações positivas com a cultura e a identidade negras. Em sua perspectiva, 0 amor à negritude é um ato de resistência e intervenção revolucionária, com o potencial de transformar o olhar e a subjetividade.

Conforme aponta hooks (1994), o movimento Black Power na década de 1960 nos Estados Unidos foi marcado pelo combate ao racismo internalizado nas dimensões estética e intelectual, por meio de formas de representação positivas e da centralidade de autores negros como referência, abordando criticamente a cultura hegemônica para a descolonização das mentes e do imaginário das pessoas negras. Segundo a autora, 0 amor próprio individual e coletivo da comunidade negra se tornou uma agenda política radical, substituindo padrões racistas por visões progressistas para contemplar a diversidade da estética negra, contestando 
a naturalização do racismo reforçada pela representação midiática, práticas educacionais, relações familiares, dentre outras formas de socialização e aprendizado.

Foram feitas diversas críticas à suposta superficialidade da questão estética - noção repudiada por hooks (1994), para quem essa dimensão ultrapassa a autoestima e a vida afetiva: "ser visto como desejável não afeta apenas a habilidade de atrair parceiros; também melhora a mobilidade social de classe em espaços públicos, em sistemas educacionais e na força de trabalho" (1994, p. 180). 0 colorismo, sistema que hierarquiza pessoas do mesmo grupo étnico-racial de acordo com 0 distanciamento do fenótipo branco nos traços e na cor da pele, foi contestado no Black Power, problematizando a vantagem das pessoas de pele clara em detrimento de seus companheiros de pele escura. Conforme observa hooks, o slogan "Black is beautiful" confrontou a inferiorização da negritude, intervindo na hierarquização em castas para valorizar a imagem negra em sua intensidade e multiplicidade.

Nesse contexto, hooks (1994) relata mudanças significativas na sociabilidade motivadas por essa intervenção político-estética, conscientizando sobre racismo e colorismo e se contrapondo às práticas cotidianas de hierarquização racial. Segundo a autora, comportamentos consolidados baseados nessas castas de cor passaram a ser questionados, problematizados e, em muitos casos, abandonados - como as punições mais severas no ambiente escolar para crianças de pele mais escura, o alisamento capilar como forma de suavização dos traços negros e adaptação a padrões estéticos brancos, práticas de hierarquização no próprio ambiente familiar, assim como a passividade individual diante da discriminação racial dirigida a outros sujeitos.

Enfatizando o potencial coletivo da transformação estética e intelectual, hooks afirma: "Esse processo de descolonização promoveu mudanças poderosas nas vidas de todas as pessoas negras nos Estados Unidos. Isso significou que, agora, nós podíamos militantemente confrontar e mudar as devastadoras consequências psicológicas do racismo internalizado" (1994, p. 175). Contestar a herança colonial foi fundamental para a construção de identidades negras orgulhosas, combativas e conscientizadas, que se juntaram à luta pelos direitos civis e conquistaram avanços significativos. Ecoando as ideias de Fanon (2008), bell hooks $(1992,1994)$ enfatiza o papel central da descolonização e educação para a consciência crítica na transformação social. Na concepção da autora, para intervir nas políticas de representação determinadas pelo colonialismo, é preciso reconhecer o poder das imagens dos meios de comunicação na construção da realidade social, articulando a organização coletiva em movimentos progressistas. 


\section{Interseccionalidade e lugar de fala}

A visão da identidade de um grupo social como fixa, predefinida e homogênea remete ao olhar colonial, que ignora a multiplicidade de experiências e particularidades dos sujeitos, objetificando-os, atribuindo ao grupo uma aparente uniformidade. Reivindicar novas perspectivas sobre as identidades negras da diáspora exige um posicionamento contra esses movimentos totalizadores, essencialistas, visto que os discursos que se pretendem universais tendem a hierarquizar pontos de vista e se organizar em torno dos sujeitos mais privilegiados de acordo com as categorias de gênero, raça, classe e sexualidade, dentre outras. Considerar uma única categoria analítica pode silenciar e invisibilizar as formas de opressão que resultam da combinação e sobreposição de dois ou mais recortes. Para contestar essa pretensa universalização da experiência e evitar a narrativa única, é preciso interseccionalizar a discussão para que ela contemple perspectivas e lugares sociais diversos.

Enfatizando a heterogeneidade de experiências históricas que compõem uma diáspora, Brah (1996) aponta as categorias de classe e gênero, dentre outras, como marcadores significativos na experiência individual e coletiva dos sujeitos diaspóricos. Para Butler (2001), as construções sociais de raça, gênero e sexualidade interagem com as questões estatais e internacionais nas novas narrativas pós-coloniais, reconfigurando as identidades na busca por direitos. Na visão da autora, essas articulações identitárias não são mero resultado de fatores étnicos e socioeconômicos, mas caracterizam a própria luta pela autodeterminação. Clifford (1994) concorda que os estudos da diáspora devem atentar para a exploração econômica e o racismo, alertando que o foco único no aspecto cultural das fronteiras limita a discussão a questões de educação e tolerância. Para 0 autor, a diversidade cultural é importante, mas quando tratada de forma isolada, não contempla as especificidades de gênero, raça e classe que configuram as interações - portanto, deve estar atrelada à transversalidade dessas demandas concretas, materiais e estruturais.

Referindo-se à ação dos estudos culturais para identificar e transformar os mecanismos de desumanização que organizam as sociedades, hooks (1994) defende um olhar interseccional, no que ela chama de abordagem holística das formas de opressão. Para a autora, o foco dessa vertente de estudos na cultura popular abre um espaço poderoso para a contestação, intervenção e transformação - em um diálogo constante com a sociedade para modificar os costumes e hábitos; educar para o desenvolvimento de uma consciência crítica e de olhares politizados, insurgentes e contra-hegemônicos; combinando teoria e prática, crítica e ação.

Trazendo sua experiência acadêmica como exemplo, hooks (1994) expressa seu profundo incômodo com lutas que se afirmam progressistas 
por repudiar uma forma de dominação, enquanto praticam outra; com sujeitos comprometidos com um ou alguns dos recortes de raça, gênero, classe, sexualidade, enquanto reproduzem, perpetuam e ativamente se beneficiam de outros. Em defesa da abordagem holística como ponto de partida para as revoluções culturais, a autora afirma que a igualdade só pode ser construída mediante 0 contraponto a todas as esferas de dominação hierárquica que implicam privilégios individuais e coletivos. Na visão de hooks (1994), se os sujeitos se comprometerem apenas com a desconstrução das políticas de dominação que os prejudicam individualmente, eles mantêm 0 vínculo com o status quo, alimentando e perpetuando esses mesmos sistemas de dominação.

Nesse sentido, hooks (1994) reafirma o caráter interdependente desses sistemas, defendendo sua transformação de maneira interligada. Essa abordagem busca evitar o que a autora chama de "pontos cegos": 0 apagamento e a invisibilização dos sujeitos vítimas de opressão social em suas múltiplas formas e combinações. Como observa hooks, a revolução cultural exige uma mudança radical no comportamento, pensamento e olhar: "Ao descolonizar nossas mentes e nosso imaginário, nós aprendemos a pensar de forma diferente, a enxergar tudo com 'os novos olhos' que Malcolm X disse que precisaríamos para entrar na luta como sujeitos e não como objetos" (1994, p. 7) - retomando a questão de tornar-se sujeito e a autodeterminação.
A abordagem interseccional e 0 processo de subjetivação, ou seja, 0 ato de tornar-se sujeito para se autodefinir e autodeterminar coletivamente, são ideias que se aproximam do conceito de lugar de fala - mais comum nas discussões feministas, mas que se aplica às demais categorias sociais de desigualdade. Elaborando o conceito a partir do feminist standpoint (ponto de vista feminista), Djamila Ribeiro (2017) desenvolve 0 lugar de fala não como um marcador pessoal, individual, mas como uma perspectiva que considera experiências de dominação e opressão coletivas, compartilhadas por grupos socialmente construídos segundo recortes como gênero, raça, classe e sexualidade. Para a autora, pensar em lugar de fala envolve questionar quem recebeu autorização e legitimidade de fala no projeto de colonização, romper com o silenciamento dos grupos subalternizados - promovendo um debate estrutural, considerando como a normatização hegemônica articula a demarcação dessas identidades de forma hierarquizada, como lugares sociais de desigualdade e vulnerabilidade.

Assim como hooks (1992) aborda a autodefinição e autodeterminação política como formas de resistência, contestando a posição historicamente imposta como objetos para se constituir como sujeitos, Ribeiro (2017) aponta a autodefinição como uma estratégia de enfrentamento à visão colonial. Trata-se de atribuir a devida relevância aos discursos de grupos subalternizados, de modo que essas pessoas possam, enfim, falar por si mesmas e serem ouvidas. Muito além da questão 
individual da legitimidade de fala, essa prática foca na dimensão estrutural, coletiva, mediante o questionamento de discursos hegemônicos - desestabilizando as ideologias dominantes e desafiando a pretensa universalização da epistemologia eurocêntrica, por meio da descolonização do conhecimento, da valorização de tradições orais populares e de saberes historicamente silenciados.

Como afirma Ribeiro, considerar outras epistemologias implica "desestabilizar e transcender a autorização discursiva branca, masculina cis e heteronormativa e debater como as identidades foram construídas nesses contextos" (2017, p. 28). 0 debate sobre a construção das identidades é fundamental para um contexto progressista de descolonização do conhecimento, na medida em que os processos culturais vigentes de invisibilização, silenciamento e apagamento estão diretamente ligados às práticas de legitimação discursiva da violência e exclusão materializadas nas relações sociais.

Trazendo aportes teóricos de Linda Alcoff (2016 apud RIBEIR0, 2017), para quem a criação e reificação de identidades é uma ferramenta colonial de administração e hierarquização dos povos, Ribeiro enfatiza: "não é possível fazer um debate amplo sobre um projeto de sociedade sem enfrentar o modo pelo qual certas identidades são criadas dentro da lógica colonial" (p. 30). Considerando as normas identitárias como mecanismos para privilegiar determinados grupos, assim como para

silenciar, segregar, excluir e violentar outros, as políticas identitárias são estruturais e, portanto, fundamentais nesse processo de descolonização. É precisamente no caráter estrutural que reside a importância do lugar de fala, ao contemplar os grupos oprimidos como sujeitos, e não mais como objetos; considerar diferentes perspectivas, origens, experiências, historiografias; reconhecer a pluralidade de saberes e formas de produção do conhecimento que constituem as sociedades. Trata-se, assim, de uma oposição direta e consciente à narrativa única da centralização epistemológica e discursiva eurocêntrica, que se pretende universal enquanto opera de forma excludente.

\section{Considerações finais}

Este artigo abordou a identidade cultural da diáspora africana na complexidade de suas relações de identificação, deslocamento e pertencimento nas sociedades em que se inserem, assim como a relação com a África em suas construções sociais, míticas, intelectuais e culturais. Foram discutidas as relações coloniais de atribuição de identidades fixas e inferiorizadas como estratégia de dominação, os movimentos de oposição e resistência a esse olhar, junto às reverberações contemporâneas desse sistema de hierarquização racial por meio das imagens e da representação nos meios de comunicação. Nessa discussão teórica sobre a descolonização das identidades 
negras, foi possível identificar dois focos de convergência: a questão da autodefinição na constituição de sua identidade como sujeitos, junto à autodeterminação política no combate à desigualdade e ao racismo estrutural; e a questão da diversidade de subjetividades, da multiplicidade de experiências, em proximidade com a importância da abordagem interseccional da diáspora.

0s discursos da diáspora negra se organizam, principalmente, em torno de processos de descolonização, por meio da educação e da transformação dos modos de representação que atuam diretamente na construção das identidades. Esse foco orienta-se pelo desenvolvimento do pensamento crítico e de novos olhares para a construção de identidades afirmativas, combativas, de resistência, para lutar coletivamente por mudanças estruturais. Sem ignorar a subjetividade individual ou as especificidades de cada comunidade da diáspora negra, é possível identificar como ponto comum essa busca pela ruptura definitiva com as relações coloniais e suas reverberações contemporâneas articuladas nos processos de dominação e hierarquização racial.

Não se trata, nesse caso, de uma homogeneização das experiências ou uma atribuição essencialista às identidades negras da diáspora, mas de práticas de resistência em resposta a processos históricos de exploração e seus resquícios nos dias atuais - que, embora apresentem diferenças entre si devido às particularidades de cada ponto da diáspora, compartilham de um terreno comum nessa busca pela autodeterminação identitária, cultural e política. A diversidade da diáspora negra, portanto, não se limita às histórias, às trajetórias e aos contextos distintos da fragmentação causada pela dispersão, mas se refere também aos sujeitos que, como grupo social, reúnem uma multiplicidade de vivências e experiências impossíveis de homogeneizar. Essas identidades serão, então, definidas por sua subjetividade e ação como sujeitos diante de marcadores de dominação que se combinam e complexificam a questão racial, evidenciando a abordagem interseccional a partir de lugares de fala contra-hegemônicos como chave para a transformação cultural decolonial e a construção de sociedades igualitárias.

\section{Referências}

BRAH, Avtar. Cartographies of Diaspora: Contesting identities. London and New York: Routledge, 1996.

BUTLER, Kim D. Defining diaspora, refining a discourse. Diaspora: A Journal of Transnational Studies, Toronto, v. 10, n. 2, p. 189-219, 2001.

CLIFFORD, James. Diasporas. Cultural Anthropology, Northampton, v. 9, n. 3, p. 302-338, aug. 1994.

DAVIS, Angela. Mulheres, raça e classe. São Paulo: Editora Boitempo, 2016. Mulheres, cultura e política. São Paulo: Editora Boitempo, 2017.

FANON, Frantz. Pele negra, máscaras brancas. Salvador: EDUFBA, 2008. 
GONZALEZ, Lélia. A categoria político-cultural de amefricanidade. In: Tempo Brasileiro. Rio de Janeiro, No. 92/93, p. 69-82, jan./jun. 1988.

HALL, Stuart. Cultural Identity and Diaspora. In: RUTHERFORD, Jonathan (Org.). Identity: Community, Culture, Difference. London: Lawrence \& Wishart, 1990. p. 222-237.

. Que "negro" é esse na cultura negra? In: SOVIK, Liv (Org.). Da diáspora: Identidades e mediações culturais. Belo Horizonte: Editora UFMG, 2003. p. 335-349.

hooks, bell. Black looks: race and representation. Boston: South End Press, 1992.

. Outlaw culture: resisting representations.

New York, London: Routledge, 1994.

RIBEIR0, Djamila. 0 que é lugar de fala? Coleção Feminismos Plurais. Belo Horizonte: Editora

Letramento, 2017. 


\begin{tabular}{|c|c|}
\hline $\begin{array}{l}\text { Black identities in diaspora } \\
\text { and the decolonization } \\
\text { of representation }\end{array}$ & $\begin{array}{l}\text { Las identidades negras de la } \\
\text { diáspora y la descolonización } \\
\text { de la representación }\end{array}$ \\
\hline $\begin{array}{l}\text { Abstract } \\
\text { This paper addresses the cultural identities of the } \\
\text { black diaspora, exploring its constitution through } \\
\text { multi-locality, the colonial historical processes of } \\
\text { racial objectification and the practices of black } \\
\text { resistance on its individual and collective dimensions. } \\
\text { Approaching the use of images and the forms of } \\
\text { representation as mechanisms to naturalize racial } \\
\text { hierarchies, this study discusses the disruption } \\
\text { of the colonial project through the development of } \\
\text { critical awareness alongside new standpoints and } \\
\text { perspectives, presenting the convergence points on } \\
\text { the identity discourses of the black diaspora. } \\
\text { Keywords } \\
\text { Black diaspora. Racism. Intersectional. }\end{array}$ & $\begin{array}{l}\text { Resumen } \\
\text { Este artículo presenta una reflexión sobre las } \\
\text { identidades culturales de la diáspora negra, } \\
\text { investigando su constitución por medio de la } \\
\text { multilocalidad, de los procesos históricos coloniales } \\
\text { de objetificación racial y de las prácticas de } \\
\text { resistencia negra en las dimensiones individual y } \\
\text { colectiva. Abordando el uso de las imágenes y de las } \\
\text { formas de representación como mecanismo para la } \\
\text { naturalización de las jerarquías raciales, este estudio } \\
\text { discute la ruptura con el proyecto colonial por medio } \\
\text { del desarrollo de la conciencia crítica junto a nuevas } \\
\text { miradas y perspectivas, presentando los puntos } \\
\text { de convergencia en los discursos identitarios de la } \\
\text { diáspora negra. } \\
\text { Palabras-clave } \\
\text { Diáspora negra. Racismo. Interseccional. }\end{array}$ \\
\hline
\end{tabular}




\section{Expediente}

A revista E-Compós é a publicação científica em formato eletrônico da Associação Nacional dos Programas de Pós-Graduação em Comunicação (Compós). Lançada em 2004, tem como principal finalidade difundir a produção acadêmica de pesquisadores da área de Comunicação, inseridos em instituições do Brasil e do exterior.

\section{E-COMPÓS I www.e-compos.org.br I E-ISSN 1808-2599}

Revista da Associação Nacional dos Programas de Pós-Graduação em Comunicação. Brasília, v.21, n.3, set/dez. 2018. A identificação das edições, a partir de 2008, passa a ser volume anual com três números. Indexada por Latindex I www.latindex.unam.mx

\section{CONSELHO EDITORIAL}

Ada Cristina Machado Silveira, Universidade Federal de Santa Maria, Brasi Alda Cristina Silva da Costa, Universidade Federal do Pará, Brasil Alfredo Luiz Paes de Oliveira Suppia, Universidade Estadual de Campinas, Brasil Ana Carolina Rocha Pessôa Temer, Universidade Federal de Goiás, Brasil Ana Regina Barros Rego Leal, Universidade Federal do Piauí, Brasil André Luiz Martins Lemos, Universidade Federal da Bahia, Brasil Angela Cristina Salgueiro Marques, Universidade Federal de Minas Gerais, Brasil Ângela Freire Prysthon, Universidade Federal de Pernambuco, Brasil Anna Cristina Pertierra, Western Sidney University, Austrália Antonio Carlos Hohlfeldt, Pontifícia Universidade Católica do Rio Grande do Sul, Brasi Arthur Ituassu, Pontifícia Universidade Católica do Rio de Janeiro, Brasil Bruno Campanella, Universidade Federal Fluminense, Brasil Bushra Hameedur Rahman, University of the Punjab, Paquistão, Paquistão Cárlida Emerim, Universidade Federal de Santa Catarina, Brasil Carlos Del Valle Rojas, Universidad de La Frontera, Chile Carlos Eduardo Franciscato, Universidade Federal de Sergipe, Brasil Cláudio Novaes Pinto Coelho, Faculdade Cásper Líbero, Brasil Danilo Rothberg, Universidade Estadual Paulista, Brasil Denise Tavares, Universidade Federal Fluminense, Brasil Diógenes Lycarião, Universidade Federal do Ceará, Brasil Dóris Martínez Vizcarrondo, Universidad de Puerto Rico Mayagüez, Porto Rico Eduardo Vicente, Universidade de São Paulo, Brasil

Eliza Bachega Casadei, Escola Superior de Propaganda e Marketing - SP, Brasil Elvira Gomes dos Reis Freitas, Universidade de Cabo Verde, Cabo Verde Eneus Trindade, Universidade de São Paulo, Brasil Erick Felinto de Oliveira, Universidade do Estado do Rio de Janeiro, Brasil Erick Torrico, Universidad Andina Simón Bolívar, Bolívia, Bolívia Erly Vieira Júnior, Universidade Federal do Espírito Santo, Brasil Fabio La Rocca, Université Paul-Valéry Montpellier 3, França Fernando Firmino da Silva, Universidade Federal da Paraíba, Brasil Francisco de Assis, FIAM-FAAM Centro Universitário, Brasil Francisco Elinaldo Teixeira, Universidade Estadual de Campinas, Brasil Francisco Gilson Rebouças Pôrto Junior, Universidade Federal do Tocantins, Brasil Francisco Sierra Caballero, CIESPAL, Equador Frederico de Mello Brandão Tavares, Universidade Federal de Ouro Preto, Brasil Gabriela Reinaldo, Universidade Federal do Ceará, Brasil Germán Rey Beltrán, Universidad Nacional de Colombia, Colômbia Gilson Vieira Monteiro, Universidade Federal do Sul da Bahia, Brasil Gustavo Daudt Fischer, Universidade do Vale do Rio dos Sinos, Brasil Gustavo Hernández Díaz, Universidad Central de Venezuela, Venezuela Heidi Figueroa Sarriera, Universidad de Puerto Rico, Porto Rico Ignacio Aguaded, Universidad Huelva, Espanha Inesita Soares de Araújo, FIOCRUZ, Brasil Itania Maria Mota Gomes, Universidade Federal da Bahia, Brasil Jiani Adriana Bonin, Universidade do Vale do Rio dos Sinos, Brasi João Carlos Ferreira Correia, Universidade da Beira Interior, Portugal Jonathan Cohen, University of Haifa, Israel José Afonso da Silva Junior, Universidade Federal de Pernambuco, Brasil José Luiz Aidar Prado, Pontifícia Universidade Católica de São Paulo, Brasil Josette Maria Monzani, Universidade Federal de São Carlos, Brasil Juçara Gorski Brittes, Universidade Federal de Ouro Preto, Brasil Julián Durazo Hermann, Université du Québec à Montreal, Canadá Juliana Freire Gutmann, Universidade Federal da Bahia, Brasil
Karla Yolanda Covarrubias, Universidad de Colima, México Laura Loguercio Cánepa, Universidade Anhembi Morumbi, Brasil Leonel Azevedo de Aguiar, Pontifícia Universidade Católica do Rio de Janeiro, Brasil Leticia Cantarela Matheus, Universidade do Estado do Rio de Janeiro, Brasil Ling Chen, Hong Kong Baptist University, China Luciana Coutinho Souza, Universidade de Sorocaba, Brasil Marcel Vieira Barreto Silva, Universidade Federal da Paraíba, Brasil Marcia Tondato, Escola Superior de Propaganda e Marketing, Brasil Márcio Souza Gonçalves, Universidade do Estado do Rio de Janeiro, Brasil Maria Ataide Malcher, Universidade Federal do Pará, Brasil Maria das Graças Pinto Coelho, Universidade Federal do Rio Grande do Norte, Brasi Maria Elena Hernández Ramirez, Universidad de Guadalajara, México Maria Elisabete Antonioli, Escola Superior de Propaganda e Marketing - SP, Brasil Maria Teresa Quiroz, Universidad de Lima, Peru Marialva Carlos Barbosa, Universidade Federal do Rio de Janeiro, Brasil Marina Poggi, Universidad Nacional de Quilmes, Argentina Marli Santos, Faculdade Cásper Líbero, Brasil Mateus Yuri Passos, Universidade Metodista de São Paulo, Brasil Mauricio Mario Monteiro, Universidade Anhembi Morumbi, Brasil, Brasil Mayka Castellano, Universidade Federal Fluminense, Brasil Mirta Varela, Universidad de Buenos Aires, Argentina

Mozahir Salomão Bruck, Pontifícia Universidade Católica de Minas Gerais, Brasil Neyla Graciela Pardo Abril, Universidad Nacional de Colombia, Colômbia Nísia Martins Rosario, Universidade Federal do Rio Grande do Sul, Brasil Olga Guedes Bailey, Nottingham Trent University, Reino Unido Paolo Demuru, Universidade Paulista, Brasil

Paolo Peverini, LUISS, Itália

Paško Bilić, Institute for Development and International Relations, Croácia Paula Melani Rocha, Universidade Estadual de Ponta Grossa, Brasil Potiguara Mendes Silveira Jr, Universidade Federal de Juiz de Fora, Brasil Rafael Cardoso Sampaio, Universidade Federal do Paraná, Brasil Rafael Tassi Teixeira, Universidade Tuiuti do Paraná, Brasil Regiane Lucas de Oliveira Garcêz, Universidade Federal de Minas Gerais, Brasil Regiane Regina Ribeiro, Universidade Federal do Paraná, Brasil Renata Pitombo Cidreira, Universidade Federal do Recôncavo da Bahia, Brasil Renato Essenfelder, Escola Superior de Propaganda e Marketing, Brasil Roberto Elísio dos Santos, Universidade Municipal de São Caetano do Sul, Brasil Robson Borges Dias, Universidade Católica de Brasília (UCB), Brasil Rodolfo Rorato Londero, Universidade Estadual de Londrina, Brasil Rosario Sanchéz Vilela, Universidad Católica del Uruguay, Uruguai Roseli Figaro, Universidade de São Paulo, Brasil Saima Saeed, Jamia Millia Islamia, India Sara Brandellero, Leyden University, Holanda Simone Maria Andrade Pereira de Sá, Universidade Federal Fluminense, Brasil Sônia Caldas Pessoa, Universidade Federal de Minas Gerais, Brasil Sun Sun Lim, Singapore University of Technology and Design, Singapura Tatiana Oliveira Siciliano, Pontifícia Universidade Católica do Rio de Janeiro, Brasil Thaïs de Mendonça Jorge, Universidade de Brasília, Brasil Valquiria Michela John, Universidade Federal do Paraná, Brasil Vicky Mayer, Tulane University, Estados Unidos da América do Norte Yamile Haber Guerra, Universidad de Oriente, Cuba 


\section{CONSELHO CIENTÍFICO}

Cristiane Freitas Gutfreind, Pontifícia Universidade Católica do Rio Grande do Sul, Brasil I Eduardo Antonio de Jesus, Universidade Federal de Minas Gerais, Brasil I Eduardo Morettin, Universidade de São Paulo, Brasil I Irene de Araújo Machado, Universidade de São Paulo, Brasil

\section{COMISSÃO EDITORIAL}

Igor Pinto Sacramento, Universidade Federal do Rio de Janeiro, Brasil I Kelly Cristina de Souza Prudencio, Universidade Federal do Paraná, Brasil | Miriam de Souza Rossini, Universidade Federal do Rio Grande do Sul, Brasil

\section{EDITORES ASSOCIADOS}

Rafael Grohmann, Faculdade Cásper Líbero, Brasil I Thaiane Moreira de Oliveira, Universidade Federal Fluminense, Brasil

\section{CONSULTORES AD HOC}

Ada Machado, Universidade Federal de Santa Maria, Brasil | Ana Carolina Escosteguy, Universidade Federal de Santa Maria, Brasil | Andrea França, Pontifícia Universidade Católica do Rio de Janeiro, Brasil | Ariane Holzbach, Universidade Federal Fluminense, Brasil | Benjamim Picado, Birkbeck College, Inglattera | Bruno Souza Leal, Universidade Federal de Minas Gerais, Brasil I Eduardo Morettin, Universidade de São Paulo, Brasil I Felipe Trotta, Universidade Federal Fluminense, Brasil | Francisco Rüdiger, Pontifícia Universidade Católica do Rio Grande do Sul, Brasil | Gislene da Silva, Universidade Federal de Santa Catarina, Brasil | Inês Vitorino, Universidade Federal do Ceará, Brasil I Isaltina Gomes, Universidade Federal de Pernambuco, Brasil I Jairo Ferreira, Universidade do Vale do Rio dos Sinos, Brasil I Karina Janz, Universidade Estadual de Ponta Grossa, Brasil | Kati Caetano, Universidade Tuiuti do Paraná, Brasil | Lilian França, Universidade Federal do Sergipe, Brasil | Liziane Guazina, Universidade de Brasília, Brasil I Márcio de Vasconcellos Serelle, Pontifícia Universidade Católica de Minas Gerais, Brasil I Marta Maia, Universidade Federal de Ouro Preto, Brasil I Maurício de Bragança, Universidade Federal Fluminense, Brasil I Nina Velasco e Cruz, Universidade Federal de Pernambuco, Brasil | Norval Baitello Jr., Pontifícia Universidade Católica de São Paulo, Brasil | Pedro Guimarães, Universidade do Estado do Rio de Janeiro, Brasil | Priscilla Perazzo, Universidade Municipal de São Caetano do Sul, Brasil I Sofia Zanforlin, International Association of Media and Communication Research, Estados Unidos I Talitha Ferraz, Escola Superior de Propaganda e Marketing, Brasil I Tattiana Teixeira, Universidade Federal de Santa Catarina, Brasil I Victa de Carvalho Pereira da Silva, Universidade Federal do Rio de Janeiro, Brasil

\section{EQUIPE DE EDITORAÇÃO}

ASSISTENTE EDITORIAL Marcio Telles | REVISÃO DE TEXTOS Fátima Áli | EDITORAÇÃO ELETRÔNICA Roka Estúdio

\section{COMPÓS I www.compos.org.br}

Associação Nacional dos Programas de Pós-Graduação em Comunicação

Presidente

Marco Roxo

Programa de Pós-Graduação em Comunicação - UFF

marcos-roxo@uol.com.br

Vice-Presidente

Isaltina Gomes

Programa de Pós-Graduação em Comunicação - UFPE

isaltina@gmail.com

Secretária-Geral

Gisela Castro

Programa de Pós-Graduação em Comunicação

e Práticas de Consumo - ESPM

castro.gisela@gmail.com

CONTATO I revistaecompos@gmail.com 